\title{
Evidence of Minor Genes around the Major Gene Controlling Acidity of Oil palm (Elaeis guineensis Jacq.) Progenies from La Dibamba Germplasm
}

Likeng-Li-Ngue Benoit Constant ${ }^{1,2}$, Ngando-Ebongue Georges Frank ${ }^{2}$, Ngalle Hermine Bille ${ }^{1}$, Ntsomboh-Ntsefong Godswill $^{1,2}$, Nsimi Mva Armand ${ }^{1}$, Bell Joseph Martin ${ }^{1 *}$

\footnotetext{
${ }^{1}$ Laboratory of Genetics and Plant Improvement, Department of Plant Biology, University of Yaounde 1, Cameroon

${ }^{2}$ Lipids Analysis Laboratory, IRAD Specialized Centre for Oil Palm Research of La Dibamba, Douala-Cameroon
}

DOI: $10.36347 /$ sajb.2020.v08i05.001

| Received: 22.04.2020 | Accepted: 03.05.2020 | Published: 12.05.2020

*Corresponding author: Bell Joseph Martin

Abstract

Original Research Article

In Cameroon, most of the crude palm oil (CPO) consumed locally is produced by the informal sector and is generally of poor quality. The quality of palm oil is mainly determined by its acidity which is generated by a very active lipase present in the mesocarp of ripe palm fruits. Previous studies showed a strong variability of this trait amongst progenies, and the segregation of forms suggested a monohybridism with dominance of the strong acidity allele. The objective of this study was to get more insights into this mechanism by explaining the phenotypic variability of palm oil acidity (POA) in view of possible production of seeds bearing this low oil acidity trait. Individual palms were grouped in classes based on their level of acidity from the mean and standard deviation. Figures of each class of acidity were compared to the theoretical proportions derived from the normal distribution using Chi square test $\left(\chi^{2}\right)$ at $5 \%$ significance threshold according to the genetic determinism of POA previously demonstrated. POA assessment of 650 palms indicated a strong variability, with values ranging from 0.5 to $42 \%$ and an average of $10 \pm 8 \%$. The normal distribution of $\mathrm{F}_{2}$ into 3 classes around $1.34 \pm 0.6,15 \pm 6$ and $21.92 \pm 5 \%$, corresponded to the genotypes «papa», "Papa» and «PaPa» respectively conferring low, average and high acidity traits. This suggest the presence of minor genes around the major gene controlling POA, with the dominance of high acidity form.

Keywords: Genetic determinism, palm oil acidity, phenotypic variability, Elaeis guineensis.

Copyright @ 2020: This is an open-access article distributed under the terms of the Creative Commons Attribution license which permits unrestricted use, distribution, and reproduction in any medium for non-commercial use (NonCommercial, or CC-BY-NC) provided the original author and source are credited

\section{INTRODUCTION}

Extracted from the mesocarp of the oil palm (Elaeis guineensis Jacq.) fruit, crude palm oil (CPO) is the most produced vegetable oil in the world ». In 2017, CPO consumption was estimated at 34 vs $29 \%$ for soya oil [1]. In Cameroon, $80 \%$ of CPO is produced by agro-industries such as SOCAPALM (25.000 ha), C.D.C (15.000 ha), PAMOL (10.000 ha), SPFS (7.000 ha) and SAFACAM (4.000 ha) while $20 \%$ is produced by smallholders of the informal sector [2]. Oil from the informal sector represents almost $90 \%$ of the locally consumed vegetable oil in Cameroon [3]. CPO is mainly composed of triglycerides or triacylglycerols which represent $95 \%$ of all constituents and minor compounds such as diacylglycerol, monoacyl glycerol and about 5\% free fatty acids (FFA), issued from the biosynthesis and / or hydrolysis of triacylglycerols. Sterol, tocopherol, pigments and metal ions are also present in CPO [4]. The fatty acid composition of crude palm oil is quite balanced between saturated and unsaturated fatty acids [27], with palmitic (C16:0) and oleic (C18:1) acids being the most present [4]. CPO quality is mainly evaluated on the basis of impurities and its acidity which is an indicator of free fatty acids (FFA) content $[5,6]$. The presence of FFA in palm oil indicates the level of oil degradation during extraction and storage. If the FFA content is high, this indicates that the fruits were damaged between harvest and extraction or that they were over-ripe before harvest [6]. Therefore, high values of acidity due to lipase activity is an indication of oil quality impairment. Without refining, such oil may be unsuitable for human consumption though refining leads to the loss of CPO nutritional value. The FFA in palm oil results from lipase activity [6-9] and high water content (when greater than $0.1 \%$ ). It was noted [10] that beside factors such as crude palm oil production and extraction methods alongside microbial lipase activities, oil palm genotype could strongly affect lipase activity and hence palm oil acidity.

In a preliminary study [11], it was demonstrated that palm oil acidity (POA) is controlled by a major locus with two alleles. The dominant allele denoted "Pa" determines high acidity while the recessive allele "pa" favours the production of oil with low acidity. 
Likeng-Li-Ngue Benoit et al., Sch Acad J Biosci, May, 2020; 8(5): 111-117

Meanwhile, among each phenotype, there is a high variability. Domonhédo et al., [12] characterized this variability and confirmed the monogenic status of POA among African palm populations from Ivory Coast, Congo, etc.

However, to the best of our knowledge, the origin of the phenotypic variability of oil acidity has not been clearly established among progenies used for improved seed production. The objective of this study was therefore to explain the phenotypic variability of CPO acidity among palm trees from various progenies of La Dibamba elite germplasm which are being used for commercial seed production, in view of possible production of seeds bearing this low oil acidity trait.

\section{Materials ANd Method Study Site}

This study was realized at La Dibamba Specialized Centre for Oil Palm Research (CEREPAH) of the Institute of Agricultural Research for Development (IRAD). La Dibamba is located in the humid tropical zone with monomodal rainfall pattern, in the Littoral Region of Cameroon. The Centre is found in the Mbongo-Ndonga zone at $3^{\circ} 54^{\prime} 62^{\prime}$ ' latitude North and $9^{\circ} 51^{\prime} 77^{\prime}$ ' latitude East, at $55 \mathrm{~m}$ above sea level. There are two distinct seasons at La Dibamba. The dry season runs from mid-October to mid-March while the rainy season goes from mid-March to mid-October. Rainfall is about $2500 \mathrm{~mm} /$ year and sunshine is $1400 \mathrm{~h} /$ year with an average annual temperature of 27.50 ${ }^{\circ} \mathrm{C} /$ year.

\section{Plant Materials}

Some 650 individual oil palm trees from the commercial seed production garden were sampled from 22 progenies, resulting from 24 parents planted in CEREPAH of La Dibamba between 1993 and 1997. The progenies sampled are presented in Table-1.

Table-1: Male and female progenies used in this study.

\begin{tabular}{|c|c|c|c|c|}
\hline $\mathbf{N}^{\circ}$ & Progenies & parents & Origin & Year of planting \\
\hline 01 & LM 19175 & LM 2509 D x LM 2509 D & \multirow[t]{3}{*}{ DA 115 D AF } & 1997 \\
\hline 02 & LM 16578 & LM 2509 D x LM 3394 D & & \multirow[t]{2}{*}{1993} \\
\hline 03 & LM 17114 & LM 3394 D x LM 3394 D & & \\
\hline 04 & LM 18801 & LM 3394 D x LM 3005 D & DA 115 D AF x D A115 D AF & \multirow[t]{8}{*}{1997} \\
\hline 05 & LM 18565 & LM 2523 D x LM 2523 D & D A115 D AF AF & \\
\hline 06 & LM 18443 & LM 2523 D x LM 2531 D & DA 115 D AF x DA 115 D AF & \\
\hline 07 & LM 19016 & LM $2531 \mathrm{D} \times \mathrm{LM} 2531 \mathrm{D}$ & \multirow{2}{*}{ DA 115 D AF } & \\
\hline 08 & LM 18688 & LM 2515 D x LM 2515 D & & \\
\hline 09 & LM 19198 & LM 2357 D x LM 2357 D & DA 5 D AF & \\
\hline 10 & LM 19171 & LM 2356 D x LM 2357 D & DA 5 D AF $x$ DA 5 D AF & \\
\hline 11 & LM 18745 & LM 5155 D x LM 5100 D & (DA 115 D x LM 269 D) x (DA 115 D x LM 269 D) & \\
\hline 12 & LM 17163 & LM2750 D x LM2749 D & (DA10 D x DA3 D) AF & \multirow[t]{2}{*}{1993} \\
\hline 13 & LM 17204 & LM3050 D x LM3034 D & (DA5 D x DA3 D) x (DA5 D x DA3D) & \\
\hline 14 & LM 17685 & LM3038 D x LM3034 D & (DA5 D x DA3 D) AF & 1993 \\
\hline 15 & LM 13533 & LM3257 D AF & DA5 D x DA3 D & 1987 \\
\hline 16 & LM 18744 & LM5216 D x LM5100 D & (DA115 D x LM269 D) x (DA115 D x LM269 D) & 1997 \\
\hline 17 & LM 16598 & LM 3043 D XLM 3038 D & \multirow[t]{2}{*}{ DA 115 D AF } & 1999 \\
\hline 18 & LM 12165 & LM 2531 D X LM 2531 D & & 1987 \\
\hline 19 & LM 19121 & LM 3005 D X LM 3005 D & DA 115 D AF & 1997 \\
\hline 20 & LM 16844 & LM 2052 T X LM 1607 P & LM 2T AF & 1993 \\
\hline 21 & PO 5669 & PO 3281 T X PO 2768 P & LM 10 T X LM $10 \mathrm{~T}$ & 1997 \\
\hline 22 & PO 5670 & PO 3281 T X PO $3281 \mathrm{~T}$ & LM $10 \mathrm{~T} \mathrm{AF}$ & 1993 \\
\hline
\end{tabular}

LM : La ME, PO : POBE, DA : DABOU ; D : Dura ; T : Tenera ; P : Pisifera AF : autofécondé (self-pollinated).

\section{METHODS}

\section{Determination of POA}

The evaluation of POA was done on oil extracted from the mesocarp of matured fruits. Bunch maturity was determined by the presence of 2 to 6 loose fruits [13]. A bunch per tree and sixteen trees at least were randomly chosen per progeny. Oil extraction was done using hexane with the Soxhlet method as described in Ngando et al., [14]. Determination of acidity was done by titration using a burette with a solution of $\mathrm{KOH} 0.1 \mathrm{~N}$ in three replicates per sample according to [15]. For this study, the threshold between high acidity and low acidity was fixed at $5 \%$ [15].

\section{Determination of minor genes around the major gene controlling POA}

In order to explain the variability of POA, individual palms were grouped in classes based on their level of acidity from the mean and standard deviation. The individuals from all the progenies were grouped per phenotype and in the $\mathrm{F}_{2}$ population according to the genetic determinism of POA previously demonstrated [11]. 
Likeng-Li-Ngue Benoit et al., Sch Acad J Biosci, May, 2020; 8(5): 111-117

Figures of each class of acidity were compared to the theoretical proportions derived from the normal distribution using Chi square test $\left(\chi^{2}\right)$ at $5 \%$ significance threshold as in Yuste-Lisbona et al., [16]. The different classes were chosen in order to study the phenotypic distribution of POA as the number of genes involved in the transmission of this trait with reference to other studies $[17,19,21]$. The threshold between high acidity and low acidity was fixed at $5 \%$ with reference to Anonym [11].

\section{RESULTS}

\section{Phenotypic classification of POA in progenies with} respect to $5 \%$ ratio

Analysis of POA of 650 progenies used in seed production showed high variability of this trait. Results showed that 228 trees produced palm oil with low acidity while 422 produced highly acidic oil. The acidity values varied from $0.55 \%$ to $42 \%$, with an average of $10 \pm 8 \%$. Among the 10 progenies issued from self-pollination, LM 19016, LM 19175 and LM 6121 are homozygous for oil with low acidity (papa). Progenies LM 19198, LM 1355 and PO 5670 are homozygous for oil with high acidity $(P a P a)$, while LM 18688, LM 18565, LM 19121 and LM 17114 have 3:1 heterozygosity ratio (Table II). Among the 12 progenies issued from cross pollination, progenies LM 19171, PO 5670, LM 17685, LM 16598, LM 17163, LM 18745 and LM 18801 are homozygous for oil with high acidity while progenies LM 16844, LM 16578, LM 18443 on one hand, and LM 17204, LM 18744 on the other hand are heterozygous respectively in 1:1 and 3:1 ratios (Table-2).

Table-2: Variability of POA among progenies

\begin{tabular}{|c|c|c|c|c|c|c|}
\hline Progenies & Number HAO & Number LOA & Total & Ratio (HOA: LAO) & $\chi^{2}$ calculated & $\chi^{2}$ theoretical \\
\hline \multicolumn{7}{|c|}{ Homogeneity for low acidity $0: 1$} \\
\hline LM 19175 & 0 & 50 & 50 & $0: 1$ & 0 & \multirow{3}{*}{3,84} \\
\hline LM 12165 & & 37 & 37 & $0: 1$ & 0 & \\
\hline LM 19016 & 0 & 55 & 55 & $0: 1$ & 0 & \\
\hline \multicolumn{7}{|c|}{ Heterogeneity $3: 1$} \\
\hline LM 17114 & 38 & 6 & 44 & $3: 1$ & 3,03 & \multirow{6}{*}{3,84} \\
\hline LM 18565 & 41 & 10 & 51 & $3: 1$ & 0,79 & \\
\hline LM 19121 & 14 & 2 & 16 & $3: 1$ & 1,33 & \\
\hline LM 18744 & 12 & 2 & 14 & $3: 1$ & 0,85 & \\
\hline LM 17204 & 23 & 2 & 25 & $3: 1$ & 3,85 & \\
\hline LM 18688 & 19 & 7 & 26 & $3: 1$ & 0,05 & \\
\hline \multicolumn{7}{|c|}{ Heterogeneity $1: 1$} \\
\hline LM 16578 & 19 & 13 & 32 & $1: 1$ & 1,25 & \multirow{3}{*}{3,84} \\
\hline LM 18443 & 35 & 40 & 75 & $1: 1$ & 0,57 & \\
\hline LM 16844 & 4 & 4 & 8 & $1: 1$ & 0 & \\
\hline \multicolumn{7}{|c|}{ Homogeneity for high acidity 1:0 } \\
\hline LM 19198 & 29 & 0 & 29 & $1: 0$ & 0 & \multirow{10}{*}{3,84} \\
\hline LM 18801 & 33 & 0 & 33 & $1: 0$ & 0 & \\
\hline LM 19171 & 27 & 0 & 27 & $1: 0$ & 0 & \\
\hline LM 13533 & 16 & 0 & 16 & $1: 0$ & 0 & \\
\hline LM 17685 & 18 & 0 & 18 & $1: 0$ & 0 & \\
\hline LM 16598 & 14 & 0 & 14 & $1: 0$ & 0 & \\
\hline LM 17163 & 29 & 0 & 29 & $1: 0$ & 0 & \\
\hline LM 18745 & 28 & 0 & 28 & $1: 0$ & 0 & \\
\hline PO 5669 & 12 & 0 & 12 & $1: 0$ & 0 & \\
\hline PO 5670 & 11 & 0 & 11 & $1: 0$ & 0 & \\
\hline
\end{tabular}

HAO: hight acidity oil, LAO: low acidity oil

Results of the POA assessment of the 650 palms showed a high variability of this trait within progenies. The acidity values were between 0.55 and $42 \%$, with an average of $10 \pm 8 \%$. For the 650 palms analyzed, 422 palms produced oil with acidity values ranging from 5.21 to $42 \%$ with an average of $15 \pm 6 \%$. For the 228 palms that produced "low acidity" oil, values ranged from 0.55 to $4.58 \%$ with an average of $1.35 \pm$ $0.57 \%$ (Table- 3 ). 
Table-3: Phenotypic distribution of POA from $\mathrm{F}_{2}$

\begin{tabular}{|l|l|l|l|l|}
\hline Populations & Number & Minimum (\%) & Maximum (\%) & Average (\%) \\
\hline \multicolumn{5}{|c|}{ Variability of POA in all the progenies } \\
\hline Total of individuals & 650 & 0.55 & 42 & $10 \pm 8$ \\
\hline Low acidity & 228 & 0.55 & 4.59 & $1.35 \pm 0.6$ \\
\hline High acidity & 422 & 5.21 & 42 & $15 \pm 6$ \\
\hline \multicolumn{5}{|c|}{ Variability of POA in F population } \\
\hline Total $\left(\mathrm{F}_{2}\right)$ & 176 & 0.55 & 42 & $12.43 \pm 8$ \\
\hline \multicolumn{5}{|c|}{ Variability of low acidity in $\mathrm{F}_{2}$ population } \\
\hline papa" population & 29 & 0.55 & 3.68 & $1.34 \pm 0.6$ \\
\hline \multicolumn{5}{|c|}{ Variability of high acidity in $\mathrm{F}_{2}$ population } \\
\hline Papa" Population & 98 & 5.29 & 15.74 & $11 \pm 3$ \\
\hline PaPa" population & 49 & 16.06 & 42 & $21.92 \pm 5$ \\
\hline Total of high acidity & 147 & 5.29 & 42 & $15 \pm 6$ \\
\hline
\end{tabular}

From a total of 22 progenies, 3 produced oil with low acidity, while 10 and 9 progenies are respectively homozygous and heterozygous for high acidity.

The results of POA analysis of 176 individuals from F2, showed that 29 individuals produced oil with low acidity, while 147 individuals produced oil with high acidity (Table-3). The acidity levels varied from 0.55 to $42 \%$ with an average of $12.43 \pm 8 \%$. The individuals constituting the $\mathrm{F} 2$ population in the ratio $3: 1$ are mainly grouped into 3 classes around $1.34 \pm 0.6,15 \pm$ 6 and $21.92 \pm 5 \%$.

\section{Distribution of POA classes and evidence of minor gene around the major gene controlling POA}

The grouping of individuals in acidity classes according to the mean and the standard deviation, showed a significant distribution:
- In the 3 classes of acidity grouping (Figure-1a), the maximum of individuals are found in the class producing oil with lower than $2 \%$ acidity and the minimum in the class of individuals producing oil with acidity greater than $14 \%$;

- In 4 classes of acidity grouping (Figure-1b), two important peaks are observed. These correspond to individuals producing oil with acidity less than $2 \%$ and those with acidity between 10 and $18 \%$;

- In 5 classes grouping (Figure-1c), two important peaks are also observed. These correspond to individuals producing oil with acidity less than $2 \%$ and those with acidity between 6 and 14\%;

- When grouping into 6 classes of acidity (Figure-1d), a single large peak is observed in the class of individuals producing oil with acidity less than $2 \%$. Above $6 \%$ acidity, the grouping of individuals shows an almost equitable distribution.

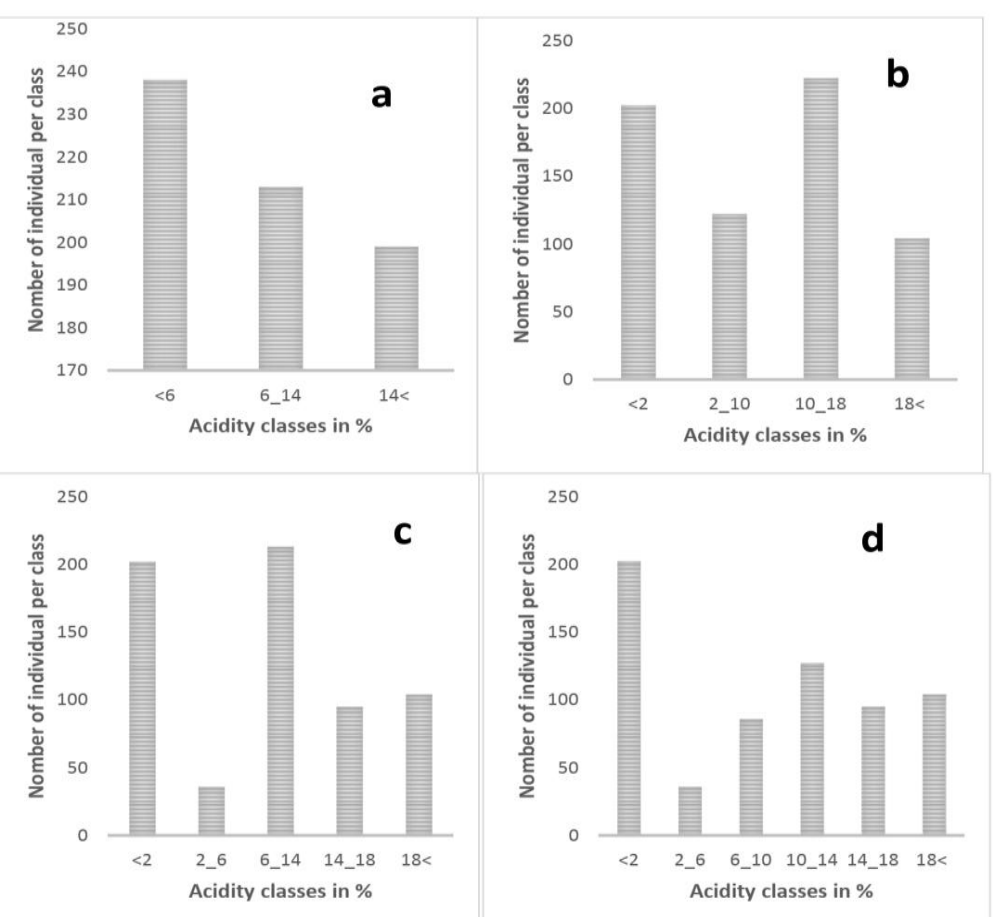

Fig-1: Classes of acidity values of all progenies. a: grouping into 3 classes, b: grouping into 4 classes, c: grouping into 5 classes, d: grouping into 6 classes 
Likeng-Li-Ngue Benoit et al., Sch Acad J Biosci, May, 2020; 8(5): 111-117

Comparison of the different acidity classes shows that no grouping follows a normal distribution where the maximum number of individuals cluster around the middle class (Table-4). This result is identical to that of individuals producing highly acidic oil, as to that of the individuals constituting $\mathrm{F}_{2}$ population.
POA of 29 individual of $\mathrm{F}_{2}$ genotype "papa", varied from 0.55 to $3.67 \%$ with an average of $1.34 \pm$ $0.6 \%$ (Table-4). The comparison between the obtained values of the class and the normal distribution of acidity class, showed that the Chi square calculated is lower than the theoretical Chi square for 5 and 6 classes, demonstrating the normal acidity distribution of this population around $1.04-1.64 \%$ (Table-4).

Table- 4: Phenotypic variability of acidity classes among all progenies. $\chi^{2}$

\begin{tabular}{|c|c|c|c|c|c|c|c|c|}
\hline \multirow{2}{*}{$\begin{array}{l}\text { Number of acidity classes } \\
\text { Populations }\end{array}$} & \multicolumn{2}{|c|}{3} & \multicolumn{2}{|c|}{4} & \multicolumn{2}{|c|}{5} & \multicolumn{2}{|c|}{6} \\
\hline & $\chi^{2}$ cal & $\chi^{2}$ Thé & $\chi^{2}$ cal & $\chi^{2}$ Thé & $\chi^{2}$ cal & $\chi^{2}$ Thé & $\chi^{2}$ cal & $\chi^{2}$ Thé \\
\hline \multicolumn{9}{|c|}{ All progenies } \\
\hline Total of individuals (650) & 4.10 & \multirow{3}{*}{3.84} & 136 & \multirow{3}{*}{7.81} & 144 & \multirow{3}{*}{9.48} & 152 & \multirow{3}{*}{11.66} \\
\hline Low acidity (228) & 145.19 & & 219.52 & & 217.37 & & 222 & \\
\hline High acidity (422) & 14.06 & & 23.63 & & 26.67 & & 37.74 & \\
\hline \multicolumn{9}{|c|}{$F_{2}$ progenies } \\
\hline Total of individuals (176) & 15.42 & \multirow{4}{*}{3.84} & 35.86 & \multirow{4}{*}{7.81} & 17.97 & \multirow{4}{*}{9.48} & 26.67 & \multirow{4}{*}{11.66} \\
\hline papa (29) & 5.5 & & 4.4 & & 6.2 & & 9.8 & \\
\hline$P a P a(49)$ & 0.87 & & 3.62 & & 2.68 & & 1.94 & \\
\hline Papa (98) & 0.06 & & 1.1 & & 1.68 & & 2.13 & \\
\hline
\end{tabular}

Figures in brackets are the total number of palms assessed.

In $\mathrm{F}_{2}$ population producing oil with high acidity, genotypes "PaPa" and "Papa" are represented according to the genetic determinism of POA. The acidity ranged from 5.29 to $42 \%$ with an average of $15 \pm$ $6 \%$, for a total of 147 individuals (Table-4).

The genotype "Papa" represents $2 / 3$ of this population. For a total of 98 individuals; results showed that the acidity ranged from 5.29 to $15.74 \%$ with an average of $11 \pm 3 \%$ (Table 4 ). The comparison between the obtained values of the class with the normal distribution of acidity, showed that the Chi square calculated was lower than the theoretical Chi square for all groupings, thus confirming the normal distribution of this population around $9.5-12 \%$ of acidity class.

The genotype " $\mathrm{PaPa}$ " represented $1 / 3$ of $\mathrm{F}_{2}$ population producing oil with high acidity, according to the genetic determinism of POA. For a total of 49 individuals, results showed that the acidity rate ranged from 16.06 to $42 \%$ with an average of $22 \pm 5 \%$ (Table-4). The comparison between the obtained values of the class and the normal distribution of acidity class, showed that the Chi square calculated was lower than the theoretical Chi square for all acidity classes, thus showing the normal distribution of this population around 19.5 - $24 \%$ of acidity (Table-4).

\section{DISCUSSION}

These results are in accordance with those obtained by [11] on 11 progenies of La Mé population where 6 progenies were homozygous and 5 progenies were heterozygous for POA. Similar results were obtained by Domonhédo et al., [22] on oil palm progenies of African origin. This variability is well observed among individuals producing palm oil with high acidity. Therefore, the diversity of this phenotype makes it difficult to separate homozygous and heterozygous individuals producing oil with high acidity among progenies. This result corroborates that of Guedes et al., [23], who assessed the variability of fruit acidity of 25 plants of Jabuticaba progeny grown in a tropical climate. León et al., [24], on one hand and Perez et al., [18] on the other hand, working respectively on the variability of free fatty acids of olive oil from progenies derived from several genetic combinations and the heritability of elevated palmitic acid content in the CAS-12 mutant on the same species, showed the influence of crossing on free fatty acid composition. The same difficulties have been observed on Brassica carinata [19]. However, the separation was easier on the acidity of the apple fruit [20].

The 03 classes of $F_{2}$ progenies that correspond to the genotype "papa", "Papa" and "PaPa" respectively, confer to palm oil low, average and high acidity. This result is in accordance with that of [18], who separated olive seeds into three classes based on their oil acidity values as 38, 19 and 7 respectively for high, intermediate, and low acidity. According to Likeng et al., [11], this is partly due to the fact that the gene responsible is dominant. Our results do not agree with the studies of Iwanami et al., [20, 18] who found difficulties in classifying fruit acidity into two classes in their study of the heritability of acidity of apple fruits and five phenotype classes of Erucic acid in Indian Mustard (Brassica juncea L. Czern \& Coss) respectively. This grouping is in accordance with the genetic determinism of palm oil acidity highlighted by previous studies $[11$, 12]. 
Likeng-Li-Ngue Benoit et al., Sch Acad J Biosci, May, 2020; 8(5): 111-117

The distribution of $F_{2}$ population on a 3:1 ratio indicates the presence of a major gene controlling POA as indicated by Likeng et al., [11] and Domonhédo et al., [22] in group A and B of Eleais guineensis populations respectively. The normal distribution of $\mathrm{F}_{2}$ population with high variability suggests the presence of minor genes around the major gene controlling POA. The same result has been obtained by Yang et al., [25] when showing that, $\mathrm{C} 18: 1$ and $\mathrm{C} 18: 2$ were controlled by a major gene, susceptible to be modified by minor genes and environmental variation. A previous study on the review of the causes of acidification of palm oil produced by smallholders identified the genotype of the plant as one of the factors involved [10]. On the contrary, Ishikawa et al., [26] showed that FFA variation could be due to the genetic mutation which is also susceptible to be modified by environmental factors. Our results are also contradictory to those of Pandey et al., [21] on one hand and Alemayehu and Becker [17] on the other, who classified acidity individuals respectively on 1:4:6:4:1 and 1:14:1 ratios, when showing that acidity was a digenic character. Perez et al., [18] indicated a trigenic transmissibility of this trait.

The impossibility to group all $\mathrm{F}_{2}$ individuals in a normal distribution has also been demonstrated in the entire population. This could be explained by the fact that, in these two groups, we can find the three genotype classes namely "PaPa", "Papa" and "papa". The same results have been obtained by Velasco et al., [19] with the difficulty to separate dominant homozygotes from heterozygotes. Meanwhile, in apple, there is good separation between low acidity individuals though with great proximity between heterozygotes and dominant homozygotes [20]. For the transmissibility of linoleic acid content in mustard N2-4961, it was possible to separate three phenotypic classes with the ratio $1: 2: 1$ in the $\mathrm{F}_{2}[19]$.

\section{CONCLUSION}

Since the highly acidic oil is unfit for human consumption, the production of hybrid palms with low acidity palm oil remains the ideal approach to enhance this product. To achieve this, a study of the individual acidity of genitors used for commercial seed production was essential. The grouping of individuals into phenotypic classes in all the population, as well as in $\mathrm{F}_{2}$ population, does not follow normal distribution. The results obtained after the POA assessment of 650 palm trees indicate a strong variability, with different values ranging from 0.5 to $42 \%$ and an average of $10 \pm 8 \%$. The normal distribution of $\mathrm{F}_{2}$ into 3 classes around $1.34 \pm 0.6$, $15 \pm 6$ and $21.92 \pm 5 \%$ respectively, suggests the presence of minor genes around the major gene controlling POA, with the dominance of high acidity form. These classes corresponding to the genotypes "papa", "Papa" and "PaPa" respectively, confer to palm oil low, average and high acidity. Due to the variability of POA, it is recommended to classify individuals according to the genotype rather than phenotype.

In perspective, this study will be extended to all the parent palms used for seed production at CEREPAH in order to identify the low acidity genitors with molecular analysis.

\section{ACKNOWLEDGEMENTS}

The authors are grateful to Institute of Agricultural Research for Development, IRAD Specialized Centre for Oil Palm Research of La Dibamba (CEREPAH), Douala-Cameroon for providing the Plant materials and laboratory equipment used in this study.

\section{REFERENCES}

1. SoyStats. World Vegetable Oil Consumption. 2018.

http://www.soystats.com/wpcontent/uploads/SoySt ats_2018.pdf (accessed on 26/03/2019).

2. Bassel El Khatib et Ludek Sisak. Productivity of Palm Oil Extraction Technology in Cameroon. Agricultura Tropica Et Subtropica. 2014;47:49-59.

3. Hirsch RD. La Filière Huile de Palme au Cameroun dans une Perspective de Relance. Agence Française de Développement, Paris (France). 1999;79.

4. Sundram K, Sambanthamurthi R \& Tan Y. Palm fruit chemistry and nutrition. Asia Pacific J. Clin. Nutr. 2003; 12:355-362.

5. Tagoe SMA, Dickinson MJ \& Apetorgbor MM Factors influencing quality of palm oil produced at the cottage industry level in Ghana. International Food Research Journal. 2012; 19:271-278.

6. De Almeida DT, Nunes IL, Conde PL, Rosa PS, Rogério WF \& Machado ER. A quality assessment of crude palm oil marketed in Bahia, Brazil. Grasas y Aceites. 2013;64:387-394.

7. Desassis A. "Palm oil acidification. Oléagineux. $1957 ; 12: 525-534$.

8. Patil KJ, Manojkumar ZC \& Raghunath TM. Lipase biodiversity. Indian J. Sci. Technol. 2011; 4:971-982.

9. Morcillo F, Cros D, Billote N, Ngando EGF, Domonhédo H, Pizot M, Cuéllar T, Espéout S, Dhouib R, Bourgis F, Claverol S, Tranbarger TJ, Nouy B \& Arondel V "Improving palm oil quality through identification and mapping of the lipase causing oil deterioration. Nat. Commun. 2013; 4:21-60.

10. Likeng-Li-Ngue BC, Ntsomboh-Ntsefong G, Ngando-Ebongue G F, Ngalle-Bille H, Nyouma, A \& Bell JM. A review of main factors affecting palm oil acidity within the smallholder oil palm (Elaeis guineensis Jacq.) sector in Cameroon. African Journal of Food Science. 2017; 11: 296-301.

11. Likeng-Li-Ngue B C, Bell JM, Ngando-Ebongue GF, Ntsomboh-Ntsefong G \& Ngalle HB. Genetic determinism of oil acidity among some DELI oil 
palm (Elaeis guineensis Jacq.) progenies. Afr. J. Biotechnol. 2016; 15:1841-1845.

12. Domonhédo H, Nodichao L, Billotte N, Ahanhanzo C \& Cros D. Variabilité génétique et compréhension de la transmission de l'acidité de l'huile dans les fruits mûrs chez le palmier à huile (E. guineensis Jacq.). J. Appl. Biosci. 2017; 119: 11871-11887.

13. Sambanthamurthi R, Sundram K, \& Yew AT. Chemistry and biochemistry of palm oil. Progress in lipid research. 2000; 39:507-558.

14. Ngando EGF, Koona P, Nouy B, Zok S, Carrière F, Zollo PHA \& Arondel V. Identification of oil palm breeding lines producing oils with low acidity. Eur. J. Lipid. Sci. Technol. 2008; 110:505-509.

15. Afnor. Recueil des Normes Françaises sur les Corps Gras, Graines. Oléagineuses, Produits Dérivés. 4th Edt. Association Française de Normalisation, Paris (France). 1988; 45.

16. Yuste-Lisbona FJ, Lopez-Sese AI \& GoMez-Guillamo NML. Inheritance of resistance to races 1,2 and 5 of powdery mildew in the melon TGR-1551". Plant breeding. 2010; 129:72-75.

17. Alemayehu N, \& Becker HC Variation and inheritance of erucic acid content in Brassica carinata germplasm collections from transmission Ethiopia. Plant Breeding. 2001; 120:331-335.

18. Perez VB, Garces R \& Fernandez-Martinez JM. Inheritance of high palmitic acid content in the sunflower mutant CAS-12 and its relationship with high oleic content. Plant Breed. 2002; 121: 49-56.

19. Velasco L, Jose M, Fernandez-Martınez, \& De Haro A. nheritance of Increased Oleic Acid Concentration in High-Erucic Acid Ethiopian Mustard. Crop Sci. 2003; I 43: 106-109.

20. Iwanami $\mathrm{H}$, Moriya $\mathrm{S}$, Kotoda $\mathrm{N}$, Mimida $\mathrm{N}$ Takahashi-Sumiyoshi $\mathrm{S} \&$ Abe K. Mode of inheritance in fruit acidity in apple analyzed with a mixed model of a major gene and polygenes using large complex pedigree. Plant Breeding. 2012; 131:322-328

21. Pandey S, Kabdal M \& Tripathi MK. Study of Inheritance of Erucic acid in Indian Mustard (Brassica juncea L. Czern \& Coss). Octa J. Biosci. 2013; 1:77-84.

22. Domonhédo H, Cros D, Nodichao L \& Billotte N Enjeux et amélioration de la réduction de l'acidité dans les fruits mûrs du palmier à huile, Elaeis guineensis Jacq. Synthèse bibliographique. Biotechnol. Agron. Soc. Environ. 2018 ; 22:1-13.

23. Guedes M NS, Rufini JCM, Azevedo AM, \& Pinto NAVD. Fruit quality of Jabuticaba progenies cultivated in a tropical climate of altitude. Fruits. 2014;69:449-458.

24. León L, Uceda M, Jiménez A, Martín LM \& Rallo L. Variability of fatty acid composition in olive (Oleaeuropaea L.) progenies. Span. J. Agric. Res. 2004; 2:353-359.

25. Yang Q, Fan C, Guo Z, Qin J, Wu J, Li Q Fu T \& Zhou Y. Identification of FAD2 and FAD3 genes in Brassica napus genome and development of allele-speci W c markers for high oleic and low linolenic acid contents. Theor. Appl Genet. 2012; 125:715-729.

26. Ishikawa G, Hasegawa H, Takagi Y. \& Tanisaka. The accumulation pattern in developing seeds and its relation to fatty acid variation in soybean. Plant breeding. 2001; 120:417-423.

27. Ntsomboh-Ntsefong G. "Genetic variability of fatty acid composition of palm oil derived from some progenies and wild accessions of Elaeis guineensis Jacq. PhD Thesis". University of Yaounde 1, (2017) 216 . 